\title{
Development of replacement priority by analysis of effect of water meter replacement
}

\author{
수도미터 교체 우선순위 선정기준 개발
}

\author{
Son, Dong-Wan ${ }^{1} \cdot \mathrm{Kim}$, Dong-Hong ${ }^{1} \cdot$ Lee, Doo-Jin ${ }^{1 *} \cdot$ Jung, Kwan-Sue ${ }^{2}$ \\ 손동완 ${ }^{1} \cdot$ 김동홍 ${ }^{1}$ 이두진 ${ }^{*} \cdot$ 정관수 $^{2}$ \\ ${ }^{1} \mathrm{~K}$-water $\cdot{ }^{2}$ Chungnam National University
}

\begin{abstract}
This study describes a reasonable planning method for water meter replacement which can minimize the metering under-registration for an increasement of revenue water. The increment analysis of real water usage was used to establish a replacement plan. The meter replacement database collected from $\mathrm{K}$ City was used as the basis of this analysis. The database included 964 connections of domestic and non-domestic consumers that had their meter replaced by aging at 2011.

The result showed that the corelation between unregistered water volume and water meter age was lower than commonly expected where the current criteria of replacement is only water meter age(8 years) excluding the meters older than 13 years. And in the analysis result of water usage for 8 years, the total amount and increment of water usage had a significant effect on unregistered water volume. However the relation was different tendency as a total volume and slope of increment. In case of total water volume was larger than 10,000, larger than 7,000 and increment of 0.0 - 0.3, larger than 6,000 and increment more than -0.3 were analysed to need a replacement because of metering under-registration.
\end{abstract}

Key words : water meter, unregistered water volume, replacement priority, water usage

주제어 : 수도미터, 불감수량, 교체우선순위, 물사용량

\section{1. 서 론}

2012년 우리나라에서 생산·공급한 수돗물의 총량은 6,029 백만 $\mathrm{m}^{3}$ 으로 이 가운데 수도요금이 부과된 유수수량은 5,064 백만 $\mathrm{m}^{3}$ (유수율 $84 \%$ ) 이고 수도요금으로 징수되지 못한 무수수량이 전 체 $16 \%$ 이며, 무수수량 중 가장 큰 비중을 차지하 는 것은 누수량으로 총 생산량의 $10.4 \%$ 인 627 백만 $\mathrm{m}^{3}$ 차지하고 있다(Ministry of Environment, 2011).

- Received 24 April 2014, revised 13 October 2014, accepted 15 October 2014.

*Corresponding author: Tel : 042-870-7320 E-mail : djlee@kwater.or.kr
한편, 유수율 관리에 있어 두 번째로 큰 볼륨을 차지하는 것은 실제로 요금을 징수하지는 못했지 만 사용상 유효했다고 인정하는 유효무수수량에 해당하는 수용가 수도미터의 불감수량이다. 실제 로 2011년 총 공급수량의 약 3.7\%인 226백만 $\mathrm{m}^{3}$ 이 요금이 징수되지 않고 손실되는 양으로 남아있 다. 수도미터 관리의 중요성은 수도사업자가 충분 히 인지하고 있는 유수율 관리목표임에도 불구하 고 관망에서의 누수와는 달리 국가에서 정한 검정 유효기간 8년(구경 $50 \mathrm{~mm}$ 이하)이 지나면 교체하 는 단순한 문제로 인식되고 있다.

수도미터의 불감율 저감과 적정 교체시기 선 정에 관한 연구는 수도미터 자체의 성능개선과 
함께 물사용량과 경과연수 등에 따른 수도미 터 오차를 분석하고 이를 토대로 경제적인 개 량시기나 개량대상 수도미터를 선정하는 방법론 에 대한 연구가 활발히 수행되어 왔다(Ahn et al. (2005)).

$\operatorname{Davis}(2005)$ 는 가정용 수도미터의 경제적 인 교체방안에 대한 연구에서 Arizona수자원국 (Arizona Department of Water Resource)에 서 1993년부터 설치 운영중인 5/8 3/4 inch 크기의 수도미터중 철거된 1,516 개의 수도미터 를 대상으로 저(0.25 gpm), 중(2 gpm), 고(15 $\mathrm{gpm})$ 유량별로 누적유량에 따른 정확도를 분석 하였다.

조사결과 저유량 조건에서는 누적유량에 따 라 유량계 오차가 크게 증가하는 경향을 나타 났고, 고유량에서도 다소 오차가 커지는 경향 을 보였다. 이러한 연구결과를 바탕으로 Arizona지역의 가정당 수도사용량(가구당 연평균 130,000 gallon)과 수도요금(가구당 월평균 \$ 33.56)을 고려하여 유량계오차에 의해 손실되는 유량과 손실비용사이의 상관관계를 이용하여 약 $1,420,000$ gallon의 누적유량이 발생한 시점에 서 수도미터를 교체하는 것이 최적의 교체 시기 임을 제안하였다.

Arregui(2011)은 수도미터의 최적 교체시기 를 계산하기 위해 수도미터의 적정구경 산정을 위한 그래프와 유사하게 Graphical Method를 사용하였다. 교체시기 산정을 위한 인자로는 수 도미터 기능저하 속도, 수돗물 판매가격, 수도미 터 구입 및 설치 비용, 물 사용량, 할인율을 선정 하였다. 여기서, 초기비용은 새 수도미터의 구매 가격 이외에도 수도미터 교체와 관련된 설치, 관 리상의 비용을 포함하는 것이다. 수돗물 판매가 격은 불감수량에 의한 실질적인 경제적 손실을 평가하는데 사용된다. 수도미터의 기능 저하 속 도는 각 수도미터의 작동원리와 설계특성에 따 른 특성곡선으로 평가하며, 수요패턴은 수도미 터의 오차가 유량에 따라 각기 상이함으로 각 수용가의 사용량과 사용빈도에 의해 결정된다.
Stoker et al. (2012)은 AWWA에서 수도계량 의 권장 교체연수(10년)에 기초하여 교체프로그 램을 계획할 것을 제안하고 있지만, 본 연구에서 사용연수, 사용누적유량별로 수도미터의 오차율 을 분석한 결과, 결정계수가 0에 가까운 상관성 이 없는 것으로 나타났다. 수도미터를 교체할 때 사용연수가 절대적인 인자임에 분명하지만, 수 명이외에 다른 중요한 인자들이 있고, 현재와 같 이 수명에 의존하여 교체하는 경우 너무 빨리 교 체하게 된다고 주장하였다. 각 수도사업자는 수 도계량의 적절한 교체를 위해서 비교유량 측정 과 같은 노력을 통하여 비용효과적인 교체계획 을 수립할 필요가 있음을 강조하였다.

본 연구에서는 상수도 유수율 저하의 원인 중 에 두 번째로 큰 비중을 차지하는 것으로 알려진 수도미터 불감수량의 효과적인 관리를 위한 수 도미터의 합리적인 교체시기 선정방법에 대하여 경과년수, 누적사용량, 사용량 변동추세 등의 인 자에 대하여 검토하고, 수도미터 교체에 따른 사 용량 변동에 기초하여 적정 교체시기와 교체우 선순위를 선정하는 방법을 제시하고자 하였다.

\section{2. 연구대상 및 방법}

\section{1 대상지역 현황}

대상지역의 급수인구는 2012년 기준 39,973 명으로 보급률은 $71.4 \%$ 이며, 일평균 공급량은 $16,821 \mathrm{~m}^{3}$, 사용량은 $11,190 \mathrm{~m}^{3}$ 으로 유수율은 $66.2 \%$ 로 나타나고 있다. 특히 계량기 불감수량 연간 $276,276 \mathrm{~m}^{3}$ 로 총급수량 대비 약 $4 \%$ 의 불 감율을 보이고 있다.

\section{2 수도미터 현황}

2012년 12월말 기준으로 대상지역내 총 수도 미터 수는 9,719전이며, 구경별로는 $15 \mathrm{~mm}$ 가 8,822전으로 전체 수도미터의 $90.8 \%$ 를 차지하 고 있으며, $20 \mathrm{~mm} \mathrm{424전(4.4 \% ),} 25 \mathrm{~mm} 271$ 전(2.8\%) 등으로 구성되어 있다.

수도미터 불감수량 저감을 위해 Table 2 와 같 
Table 1. Current state of water meter in study area

\begin{tabular}{|c|c|c|c|c|c|c|c|c|c|}
\hline \multirow{2}{*}{ Item } & \multirow{2}{*}{ Total } & \multicolumn{8}{|c|}{ Water meter size $(\mathrm{mm})$} \\
\hline & & 15 & 20 & 25 & 32 & 40 & 50 & 75 & 100 \\
\hline Number & 9,719 & 8,822 & 424 & 271 & 3 & 68 & 76 & 49 & 6 \\
\hline ratio & $100 . \%$ & $90.8 \%$ & $4.4 \%$ & $2.8 \%$ & $0.0 \%$ & $0.7 \%$ & $0.8 \%$ & $0.5 \%$ & $0.1 \%$ \\
\hline
\end{tabular}

Table 2. Current state of water replacement in study area

\begin{tabular}{|c|c|c|c|c|c|c|c|c|c|c|}
\hline \multicolumn{2}{|r|}{ Item } & Total & $15 \mathrm{~mm}$ & $20 \mathrm{~mm}$ & $25 \mathrm{~mm}$ & $32 \mathrm{~mm}$ & $40 \mathrm{~mm}$ & $50 \mathrm{~mm}$ & $75 \mathrm{~mm}$ & $100 \mathrm{~mm}$ \\
\hline \multicolumn{2}{|r|}{ Total } & 4,236 & 3,814 & 206 & 114 & 2 & 31 & 28 & 37 & 4 \\
\hline \multirow{4}{*}{$2010 \mathrm{yr}$} & Sub total & 372 & 323 & 25 & 15 & 2 & 3 & 3 & - & 1 \\
\hline & Timeworn & 351 & 311 & 22 & 11 & 2 & 2 & 3 & - & - \\
\hline & Failure & 16 & 6 & 3 & 4 & - & 1 & - & - & 1 \\
\hline & Freeze and burst & 6 & 6 & - & - & - & - & - & - & - \\
\hline \multirow{4}{*}{$2011 \mathrm{yr}$} & Sub total & 2,414 & 2,161 & 142 & 61 & - & 16 & 15 & 18 & 1 \\
\hline & Timeworn & 1,940 & 1,738 & 121 & 48 & - & 12 & 12 & 9 & - \\
\hline & Failure & 87 & 64 & 2 & 6 & - & 2 & 3 & 9 & 1 \\
\hline & Freeze and burst & 387 & 359 & 19 & 7 & - & 2 & - & - & - \\
\hline \multirow{4}{*}{$2012 \mathrm{yr}$} & Sub total & 1,450 & 1,330 & 39 & 38 & - & 12 & 10 & 19 & 2 \\
\hline & Timeworn & 1,349 & 1,249 & 34 & 34 & - & 10 & 8 & 12 & 2 \\
\hline & Failure & 51 & 34 & 3 & 3 & - & 2 & 2 & 7 & - \\
\hline & Freeze and burst & 50 & 47 & 2 & 1 & - & - & - & - & - \\
\hline
\end{tabular}

Table 3. Current state of excluded water meter by excessive water usage change

\begin{tabular}{|c|c|c|c|c|c|c|}
\hline Item & Total & Indoor leakage & Change of resident & Excessive fluctuation & Failure & Duplication \\
\hline Number of water meter & 625 & 235 & 69 & 310 & 11 & 95 \\
\hline
\end{tabular}

이 2010년 9월부터 수도미터를 지속적으로 교 체하고 있다. 교체 대상은 노후(검정유효기간 초 과), 고장(회전불량, 불회, 지침부 파손 등), 동 파 수도미터에 대해 실시하고 있다.

본 연구의 목적은 수도미터 교체 전후 1 년간 사용량 증감을 분석하고, 증감형태별로 수도미 터 경과년수, 총사용량, 사용량 변화경형(기울 기) 등과의 관계를 분석하여 수도미터 교체 우선 순위를 선정하는 새로운 방법을 제시하는 것이 며, 이를 위하여 노후가 아닌 고장 및 동파에 따 른 수도미터 교체는 분석 대상에서 제외하였다.

물사용 패턴 과대변화 수용가를 분석할 결과 Table 3 과 같으며, 이중 중복을 제외한 전수는 총 530전으로 총 964전 중 55\%가 물사용 패턴 이 과대하게 변화하는 것으로 분석되었다.

\section{3 연구방법}

본 연구에서는 기 교체된 434전의 수도미터 에 대하여 교체 전후 사용량 증감을 분석하였다. 사용량 증감 분석은 분석대상 수도미터가 모두 2011년에 교체된 점을 고려하여 교체 전 사용량 (2010년)과 교체 후 사용량(2012년)을 비교하여 분석을 실시하였다. 수도미터의 사용량 변화에 영향을 미치는 외부요인을 배제하기 위하여 옥 내누수, 명의변경, 과다한 사용량변화가 나타난 수도미터에 대하여 다음과 같은 기준에 따라 분 석에서 제외하였다.

옥내누수의 경우 월간사용량이 전년도 월 최 대치를 2개월 연속 초과하는 수도미터로 판정하 였고, 명의변경의 경우 수도요금관리스템을 통 하여 조사기간 중에 세대주가 변경된 가구를 제 
Table 4. Trend of water usage

\begin{tabular}{|c|c|c|c|c|c|c|c|c|c|c|}
\hline Item & '03 & '04 & '05 & '06 & '07 & '08 & '09 & '10 & '11 & '12 \\
\hline $\begin{array}{c}\text { Water usage } \\
\left(103 \mathrm{~m}^{3} / \mathrm{yr}\right)\end{array}$ & 119.1 & 120.4 & 119.1 & 117.6 & 117.9 & 114.6 & 114.9 & 111.5 & 115.0 & 118.0 \\
\hline
\end{tabular}

Table 5. Water usage changing by water meter replacement

\begin{tabular}{|c|c|c|c|}
\hline \multicolumn{2}{|c|}{ Water usage $\left(\mathrm{m}^{3} / \mathrm{yr}\right)$} & Change volume $\left(\mathrm{m}^{3} / \mathrm{yr}\right)(\mathrm{C}=\mathrm{B}-\mathrm{A})$ & $\begin{array}{c}\text { Change ratio } \\
(\mathrm{C} / \mathrm{A} \times 100 \%)\end{array}$ \\
\hline \hline $2010(\mathrm{~A})$ & $2012(\mathrm{~B})$ & 6,477 & $+5.8 \%$ \\
\hline
\end{tabular}

Table 6. Effect of water meter replacement

\begin{tabular}{|c|c|c|c|c|c|c|c|c|}
\hline \multicolumn{4}{|c|}{ Number of water meter } & \multicolumn{3}{c|}{ Change volume $\left(\mathrm{m}^{3} / \mathrm{yr}\right)$} & \multicolumn{3}{c|}{ Change volume per water tap $\left(\mathrm{m}^{3} / \mathrm{yr} / \operatorname{tap}\right)$} \\
\hline Total & Increasing & Decreasing & Total & Increasing & Decreasing & Total & Increasing & Decreasing \\
\hline 434 & 239 & 195 & 6,477 & 18,423 & 11,946 & 15 & 77 & 61 \\
\hline
\end{tabular}

외하였으며, 물사용량 과다변경의 경우 8년간 연간 사용량이 $\mu$ (평균 $\pm 2 \sigma$ (표준편차)를 초과 하는 경우에는 편차과대 수용가로 분류하였다.

\section{3. 결과 및 고찰}

\section{1 수도미터 교체 전후 사용량 증감 분석}

총 964전 중 물사용 패턴 과대변화 수용가 (530전)을 제외한 434전에 대해 수도미터 교체 전후 사용량 증감 현황을 분석하였다. 또한, 사 용량 증감 현황과 경과년수, 총사용량, 기울기와 의 관계를 분석하였다. 참고로 연도별 사용량 현 황을 살펴보면, 〈Fig. 5.9〉와 같이 2004년을 정 점으로 사용량이 지속적으로 감소하여 2010년 에 최소를 보이다가 2011년 이후에는 상승하는 추세에 있다.

분석결과 Table $5 \sim 6$ 과 같이 수도미터 교 체 후 사용량은 $6,477 \mathrm{~m}^{3}$ 년이 증가하여 증가비 율은 $5.8 \%$ 로 분석되었다. 또한 434전 중 $55 \%$ 인 239전의 사용량이 $18,423 \mathrm{~m}^{3}$ 년 증가하였 고, $45 \%$ 인 195 전의 사용량이 $11,946 \mathrm{~m}^{3}$ 년 감 소한 것으로 나타났다. 보편적으로 수도사업자 는 수도미터를 교체하여 성능을 유지하거나 개 선하여 사용량이 증가될 것으로 기대하나 수도 미터를 교체 후에도 사용량이 감소할 수 있는 것
으로 나타났다.

\section{2 경과연수별 수도미터 교체 전후 사용량 증 감 분석}

경과년수별 사용량 증감 분석은 분석대상 수 도미터가 모두 2011년에 교체된 점을 고려하여 교체년도에서 설치년도를 감하여 경과년수를 산 출하였다. Fig. 1(a)과 같이 경과년수는 $8 \sim 33$ 년으로 다양하며, $8 \sim 12$ 년이 전체의 약 $86 \%$ 로 대부분을 차지하고 있으며, 특히 12 년이 전체의 $42 \%$ 로 가장 많은 것으로 분석되었다.

경과년수별 사용량 증감량을 살펴보면, Fig. $1(\mathrm{~b})$ 와 같이 경과년수가 12 년 이내의 경우 경과 년수가 증가할수록 수도미터 교체 전후 사용량 의 증가와 감소가 발생하나, 경과년수가 13 년 이 상의 경우 경과년수에 상관없이 수도미터 교체 후 사용량 모두 증가하는 것으로 나타났다. 또한 경과년수별 사용량 전당증감량을 살펴보면 Fig. 1 (c)와 같이 경과년수가 12 년 이내의 경우 사용 량이 증가한 수도미터는 경과년수가 증가할수록 전당증감량이 다소 증가하는 경향을 보이나, 사 용량이 감소한 수도미터는 경과년수와 상관없이 전당증감량은 일정한 경향을 보인다.

보편적으로 경과년수가 증가하면 수도미터가 


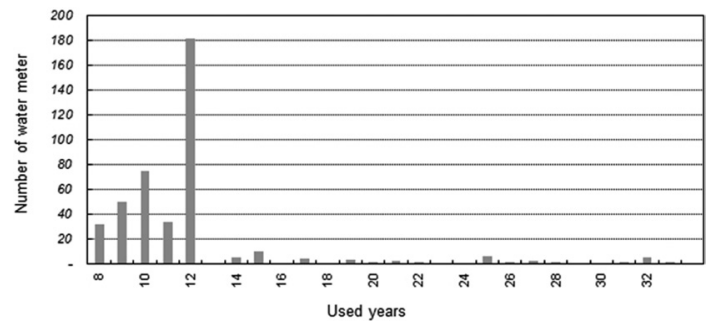

(a) Number of water meter

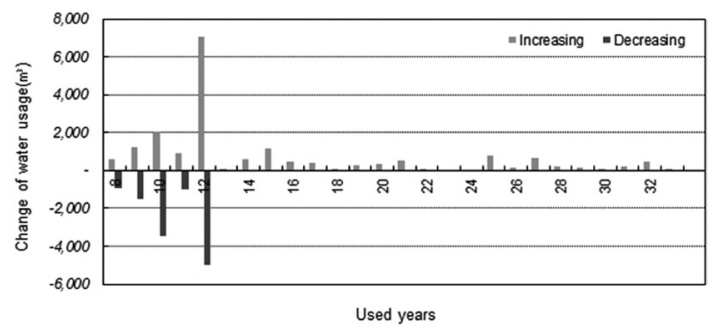

(b) Change of water usage

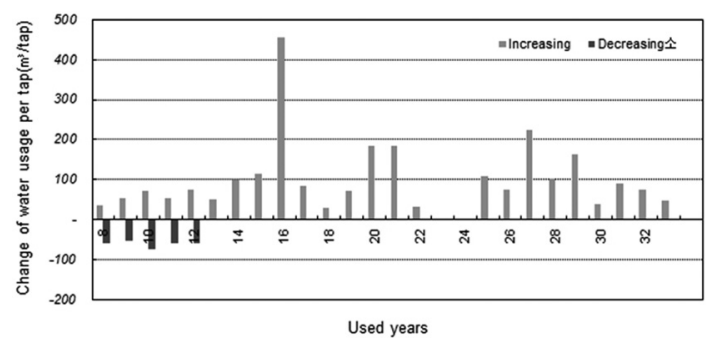

(c) Change of water usage per tap

Fig. 1. Number of water meter and Change of water usage volume by used years.

점진적으로 노후되어 수도미터 교체 후 사용량 이 모두 증가할 것으로 예상한다. 그러나 경과년 수별 사용량 증감 현황을 분석한 결과, 경과년수 가 12 년 이내의 경우 수도미터 교체 후에도 사 용량이 감소하는 경우가 나타났으며, 경과년수 가 13 년 이상의 경우 수도미터 교체 후 사용량이 모두 증가하는 경향을 보였으나, 그 증가량과 경 과년수와의 상관관계는 적은 것으로 분석된다.

\section{3 총사용량별 수도미터 교체 전후 사용량 증 감 분석}

총사용량은 수도미터가 설치되어 철거되기 전까지 계량된 총물량으로 철거시 지침값을 활 용하여 분석하였다. 또한 요금관리시스템 상에

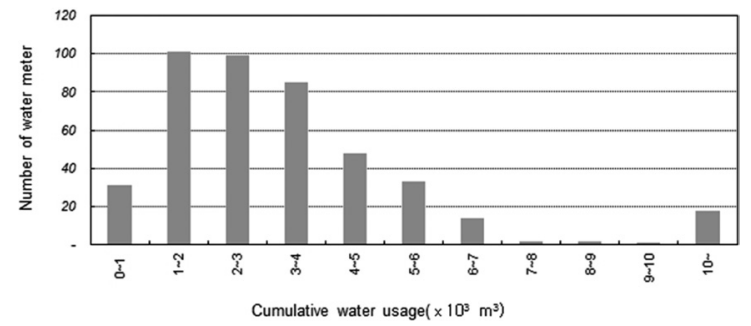

(a) Number of water meter

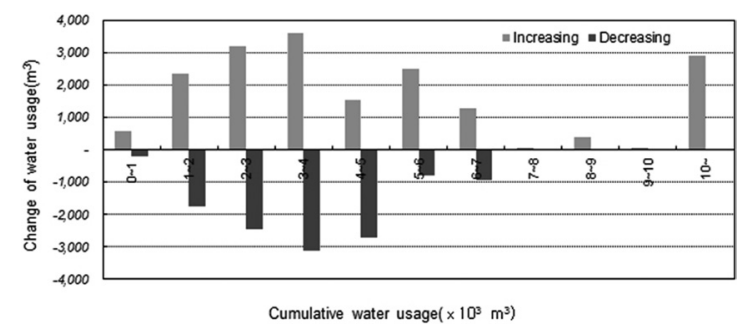

(b) Change of water usage

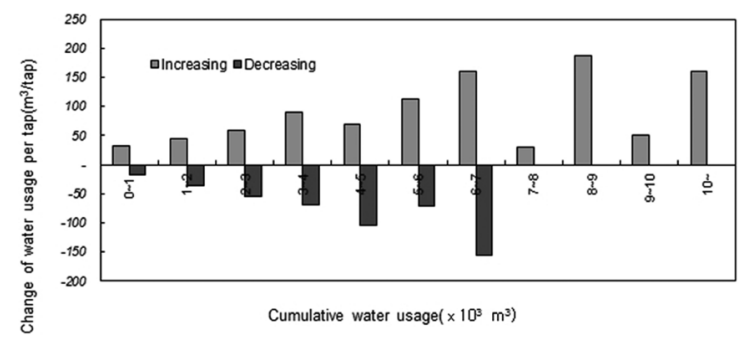

(c) Change of water usage per tap

Fig. 2. Number of water meter and Change of water usage volume by cumulative water usage.

서 관리되고 있는 수용가 사용량은 2003년부 터로 2003 2010년 총 8년간의 사용량 합계 와 비교하여 분석하였다. 이중 일부는 $15 \mathrm{~mm}$ 수도미터 최대기록값 $\left(9,999 \mathrm{~m}^{3}\right)$ 을 고려할 때, $10,000 \mathrm{~m}^{3}$ 을 초과하여 사용된 것으로 분석되어 지침값과 8년간 사용량을 비교분석하여 보정하 였다(예를들면, 1999 년 설치된 수도미터의 철거 지침은 $6,120 \mathrm{~m}^{3}$ 이나, 8 년간 사용량이 11,243 $\mathrm{m}^{3}\left(1,405 \mathrm{~m}^{3}\right.$ 년 $)$ 으로 경과년수 12 년 고려시 총 사용량은 $16,864 \mathrm{~m}^{3}\left(12\right.$ 년 $\times 1,405 \mathrm{~m}^{3}$ 년 $)$ 으로 추정되며, $1 \mathrm{~mm}$ 최대기록값 $\left(9,999 \mathrm{~m}^{3}\right)$ 을 초과 하여 다시 “0”값부터 계측되었기 때문으로 실제 총사용량은 $16,120 \mathrm{~m}^{3}$ 으로 보정하였다.)

총사용량은 평균이 $3,364 \mathrm{~m}^{3}$ 로 최소 $216 \mathrm{~m}^{3}$, 최대 $19,441 \mathrm{~m}^{3}$ 으로 다양하며, Fig. 2(a)와 같 
이 $0 \sim 6$ 천 $\mathrm{m}^{3}$ 이 전체의 약 $91 \%$ 로 대부분을 차 지하고 있다. 총사용량별 사용량 증감량을 살펴 보면, Fig. 2(b)와 같이 총사용량이 4 천 $\mathrm{m}^{3}$ 이내 의 경우 총사용량이 증가함에 따라 수도미터 교 체 전후 사용량 증감량 또한 증가하는 경향을 보 이나, 총사용량이 5 천 $\mathrm{m}^{3}$ 이상의 경우 총사용량 이 증가함에도 불구하고 수도미터 교체 전후 사 용량 증감량이 감소하는 경향으로 나타났다. 또 한 총사용량별 사용량 전당증감량을 살펴보면, Fig. 2(c)와 같이 총사용량이 7 천 $\mathrm{m}^{3}$ 이하의 경 우 총사용량이 증가함에 따라 전당증감량 또한 증가하는 경향이나, 총사용량이 7 천 $\mathrm{m}^{3}$ 이상의 경우 총사용량 증가에 상관없이 수도미터 교체 전후 사용량 증감량이 모두 증가하는 것으로 분 석되었다.

일반적으로 수도미터의 누적사용량이 증가하 면 수도미터가 점진적으로 노후되어 수도미터 교체 후 사용량이 증가할 것으로 기대한다. 그러 나 총사용량별 사용량 증감 현황을 분석한 결과,
총사용량이 7 천 $\mathrm{m}^{3}$ 이하의 경우 총사용량이 증 가함에 따라 사용량 증감량도 증가하는 경향을 보이고 있으며, 총사용량이 증가함에도 불구하 고 감소량 또는 증가하는 것으로 분석되었으며, 총사용량이 7 천 $\mathrm{m}^{3}$ 이상의 경우 총사용량 증가 에 상관없이 수도미터 교체 후 사용량이 모두 증 가하는 것으로 분석되었다.

\section{4 사용량 경향별 수도미터 교체 전후 사용량 증 감 분석}

요금관리시스템 상에서 관리되고 있는 수용가 사용량은 2003년부터로 2003 2010년 총 8년 간의 월 사용량을 활용하여 기울기를 분석하였 다. 여기서 기울기는 사용량의 점진적인 변화 경 향을 의미하며, 현재사용량 대비 교체 유량계의 2003년 유량대비 현재유량 차이의 비율로 산정 하고, 이는 실제사용량의 변화와 수도미터의 오 차가 누적하여 나타나는 결과이다.

Fig. 3과 같이 월별 사용량 경향은 $-0.7 \sim$

Table 7. Number of water meter, Change of water usage, and water usage per tap by water usage trend slope

\begin{tabular}{|c|c|c|c|c|c|c|c|c|}
\hline \multicolumn{2}{|c|}{ Items } & Total & $-0.6 \sim-0.7$ & $-0.5 \sim-0.6$ & $-0.4 \sim-0.5$ & $-0.3 \sim-0.4$ & $-0.2 \sim-0.3$ & $-0.1 \sim-0.2$ \\
\hline \multirow{3}{*}{$\begin{array}{l}\text { Number of Water } \\
\text { meter }\end{array}$} & Total & 434 & 2 & 2 & 2 & 8 & 19 & 58 \\
\hline & Increasing & 239 & 2 & 2 & 2 & 8 & 11 & 34 \\
\hline & Decresing & 195 & - & - & - & - & 8 & 24 \\
\hline \multirow{3}{*}{$\begin{array}{c}\text { Change of water } \\
\text { usage }\end{array}$} & Total & 6,477 & 111 & 314 & 495 & 1,422 & 946 & 954 \\
\hline & Increasing & 18,423 & 111 & 314 & 495 & 1,422 & 1,314 & 2,447 \\
\hline & Decresing & $-11,946$ & - & - & - & - & -368 & $-1,493$ \\
\hline \multirow{3}{*}{$\begin{array}{l}\text { Change of water } \\
\text { usage per tap }\end{array}$} & Total & 682 & 56 & 157 & 248 & 178 & 73 & 10 \\
\hline & Increasing & 1,389 & 56 & 157 & 248 & 178 & 119 & 72 \\
\hline & Decresing & -706 & - & - & - & - & -46 & -62 \\
\hline \multicolumn{2}{|c|}{ Items } & $0.0 \sim-0.1$ & $0.0 \sim 0.1$ & $0.1 \sim 0.2$ & $0.2 \sim 0.3$ & $0.3 \sim 0.4$ & $0.4 \sim 0.5$ & \\
\hline \multirow{3}{*}{$\begin{array}{l}\text { Number of Water } \\
\text { meter }\end{array}$} & Total & 158 & 103 & 47 & 23 & 7 & 5 & \\
\hline & Increasing & 90 & 59 & 17 & 11 & 2 & 1 & \\
\hline & Decresing & 68 & 44 & 30 & 12 & 5 & 4 & \\
\hline \multirow{3}{*}{$\begin{array}{c}\text { Change of water } \\
\text { usage }\end{array}$} & Total & 3,323 & 1,390 & $-1,713$ & 258 & -293 & -730 & \\
\hline & Increasing & 5,893 & 3,683 & 803 & 1,648 & 117 & 176 & \\
\hline & Decresing & $-2,570$ & $-2,293$ & $-2,516$ & $-1,390$ & -410 & -906 & \\
\hline \multirow{3}{*}{$\begin{array}{l}\text { Change of water } \\
\text { usage per tap }\end{array}$} & Total & 28 & 10 & -37 & 34 & -24 & -51 & \\
\hline & Increasing & 65 & 62 & 47 & 150 & 59 & 176 & \\
\hline & Decresing & -38 & -52 & -84 & -116 & -82 & -227 & \\
\hline
\end{tabular}




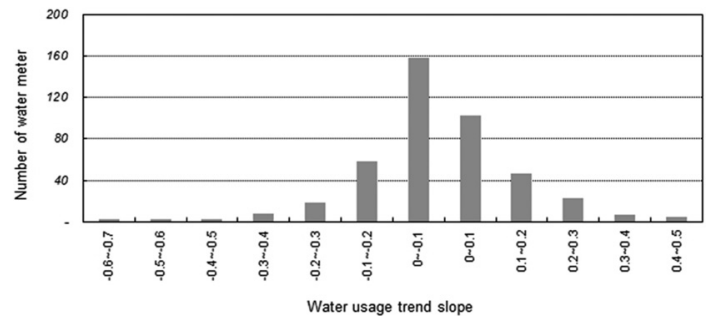

(a) Number of water meter

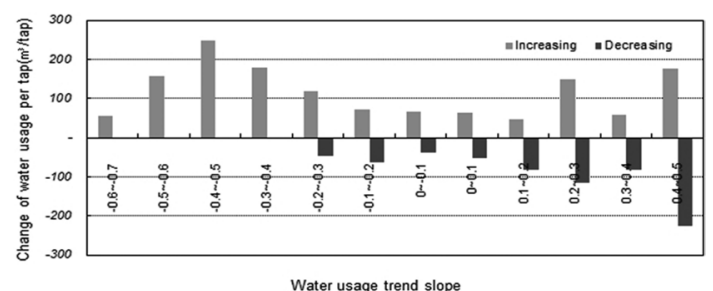

(b) Change of water usage

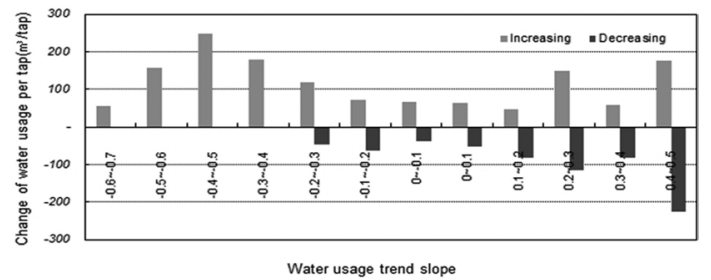

(c) Change of water usage per tap

Fig. 3. Number of water meter and Change of water usage volume by water usage trend slope.

0.4 로 변동되며, $-0.2 \sim 0.2$ 사이에 전체의 약 $84 \%$ 로 대부분을 차지하고 있는 것으로 분석되 었다.

기울기별 사용량 변화를 살펴보면, Fig. 3(a) 와 같이 기울기 절대값이 커질수록 수도미터 교 체 전후 사용량의 변화가 감소하는 것으로 나타 났다. 이는 물사용량의 변화가 큰 경우 수도미터 의 오차보다 실제 사용량의 변화가 더 크게 영향 을 미치는 것을 의미한다. 반면에 Fig. 3(c)와 같 이 수도전당 사용량 변화를 살펴보면, 교체전 사 용량의 기울기가 양인 경우 교체이후 사용량의 증가와 감소가 모두 나타났으나, 교체이전 사용 량이 점진적으로 줄어들고 있던 수도미터의 경 우 수도미터 교체이후 사용량이 증가하는 것이 뚜렷하게 나타나 그동안 수도미터 불감이 누적 되고 있었음을 간접적으로 추정할 수 있었다. 특
히 월간사용량 경향이 -0.3 보다 더 크게 감소하 는 경우에는 수도미터 교체후 사용량 증가(미감 지 유량해소)가 분명한 것으로 나타났다.

\section{4. 결 론}

본 연구는 기 교체된 수도미터에 대해 사용량 증감원인 및 효과를 분석하여 효율적인 수도미 터 교체 우선순위를 제시하고자 하였다. 국내외 적으로 그간의 연구가 대부분 수도미터 불감율 조사 및 개선방안 도출에 머물렀으나, 실제 현 장에서 수도미터 교체후 사용량 증감분석을 통 한 수도미터 교체 우선순위를 분석하였다는 데 에 의의가 있다. 본 연구로부터 얻은 결론은 다 음과 같다.

첫째, 경과년수가 증가할수록 수도미터 교체 후 사용량이 증가할 것으로 판단되나, 경과년수 12 년까지는 수도미터 교체후에도 사용량의 증가 와 감소가 모두 나타났으나, 경과년수가 13년 이 상 부터는 수도미터 교체 후 사용량이 모두 증가 하는 경향을 보였다.

둘째, 수도미터의 통과유량 즉 누적사용량이 증가하는 경우 기계식 수도미터의 오차누적에 의해 수도미터 교체후 사용량 변화가 클 것으로 예상되었으며, 총사용량이 7 천 $\mathrm{m}^{3}$ 이상의 경우 수도미터 교체 후 사용량이 모두 증가하는 것으 로 분석되었다.

셋째, 물사용 경향에서 사용량 기울기의 절대 값이 커짐에 따라 전당증감량이 증가하는 경향 을 보이나, 전당감소량 또한 증가하는 것으로 나 타났으며, 기울기가 -0.3 이하인 경우에는 기울 기에 상관없이 수도미터 교체 후 사용량이 모두 증가하는 것으로 분석되었다.

따라서, 본 대상지역에 적용된 기계식 수도 미터의 경우 경과년수 13 년 이상, 총사용량이 7 천 $\mathrm{m}^{3}$ 이상, 월간 사용량 변화경향(기울기)이 -0.3 이상인 경우에 수도미터 교체 후 미감지 유량이 해소되어 사용량이 모두 증가하는 결과 를 보였다. 
수도미터 교체의 주목적이 오차누적에 의한 미감지 유량을 저감하는 것이므로 본 연구에서 와 같이 다양한 조건에서 수도미터 감지유량 변 화를 분석함으로써, 유효검증기간 8년 이상 수 도미터를 일괄 교체하던 방식에 비해 보다 과학 적으로 수도미터 교체순위를 선정할 수 있을 것 으로 기대된다.

\section{References}

Ministry of Environment(2011), Statistics of water works

Ahn, J. C., Ha, S. H., Jeong, P. S., Choi, J. S., and Koo, J. Y. (2005), A Study on Underregistration of $13 \mathrm{~mm}$ Water Meter, Journal of Korean Society of Water and Wastewater, 19, pp 506-514

Davis, S.E.(2005), Residential Water Meter Replacement Economics, Leak 2005 Conference,

Arregui, F., Cobacho, R., Cabrera, E., Jr., and Espert, V. (2011). Graphical Method to Calculate the Optimum Replacement $\mathrm{Pe}-$ riod for Water Meters, J. Water Resour. Plann. Manage., 137(1), $143-146$.

Stoker, D.M.(2012), Flow Measurement Accuracies of In-service Residential Water $\mathrm{Me}-$ ters, Journal AWWA, 104, 637-642. 